\title{
Two Dimensional Static Mechanical Analysis of Laminated Composite Tube Using ABCDE Matrix with No Correction Factor
}

\author{
Arno Roland Ngatcha Ndengna ${ }^{1}$, Joel Renaud Ngouanom Gnidakouong ${ }^{2 *}$, \\ Achille Njomoué Pandong ${ }^{1}$, Ekmon Mbangue ${ }^{1}$
}

${ }^{1}$ Department of Maritime and Port Engineering, Laboratory of Energy Modeling, Materials and Methods, National Higher Polytechnic School of Douala ,University of Douala, P.O.BOX: 2107

Douala, Cameroon.

${ }^{2}$ Department of Automotive and Mechatronic Engineering, Laboratory of Energy Modeling, Materials and Methods, National Higher Polytechnic School of Douala, University of Douala, P.O.BOX: 2107,

Douala, Cameroon.

Email: ngouanom@hotmail.com (Joel Renaud Ngouanom Gnidakouong)

Received: February 2, 2021. Revised: July 20, 2021. Accepted: August 23, 2021. Published: August 25, 2021.

\begin{abstract}
Accurate modeling and prediction of materials properties is of utmost importance to design engineers. In this study, newly developed two-dimensional laminate constitutive equations (LCE) were derived directly from an existing shell model without using a classical correction factor. The resulted LCEs were subsequently used for the first time to analyze a laminated composite tube (LCT) subjected to in plane-loading. This led to additional composite-shell stiffness coefficients which are not currently available in some LCEs. The strains and stresses distribution fields were computed via Matlab. The accuracy and robustness of our analytical method were proven by opposing the as-obtained results of thick and thin LCTs with that of existing theories which use a correction factor. An excellent convergence was observed. Whereas a lower convergence was observed in the case of a laminated shell plate. Results also showed that the thickness ratio $\chi\left(2 \chi=\frac{h}{R}\right)$ considerably influences the mechanical behavior of the LCT. In
\end{abstract}

fact when $\chi<0.1$, the distribution of stresses and strains of the tube were the same for the two opposed theories. When $\chi>0.1$, the distribution of stresses and strains were not the same, hence the contribution of our ABCDE matrix. The new mechanical couplings in our LCE could be well illustrated in a finite element package with visualization tools to observe some intricate deformations which are yet to be seen. Thus the outcome of this work will be of particularly interest to promote advanced scientific and structural engineering applications.

Keywords - Laminated Constitutive Equation (LCE), Mechanical couplings, interlinear stresses analytical formulation, Laminated Composite Tube, Computational solutions.

\section{INTRODUCTION}

Investigations on composite shell structures is of major interest to many researchers in numerous fields. Beside their attractive curved structures which prompts several 
industrial applications, they also possess general interesting features such high modulus/weight and strength/weight ratios, excellent fatigue properties, and non-corroding behaviour. All of which are driving more efforts in the modelling analysis of these structures for quality assurance and increasing applications in numerous sectors such as aerospace, automotive, marine, and piping industries [1]. For structural applications, preference is usually given to continuous fiber composites due to their higher directional strength and modulus than those made with discontinuous fiber, [2]. A more balanced characteristic can be obtained with woven, bidirectional, or randomly distributed [3]. Accuracy in prediction analysis is a challenging problem and requires a great understanding of the mechanical behaviour at micro-macro-level of composite laminated shells. The complexity in designing these special structures stems from their heterogeneity, that is the point-to-point anisotropy of shells owing to their curved shape [4]. In literature, there are multitude of reports on their analysis [5], [6] , [7], [8], [9], [10], [11].

The modelling of composite laminated shells is usually classified into two categories, which are the single layer and the layer wise models. The single-layer approach comprises of the classical shell theory (CST), the firstorder shear deformation theory (FSDT) [12], the higher order shear deformation theory (HSDT) [13], [14] the refined theory for laminated anisotropic cylindrical shells [15], [16] and some others shell models as that suggested by [17]. M. Sayir et al [18] analyzed a composite laminated tube and described the limitations of CLT for cylindrical geometries. An alternative was proposed to give a more accurate solution. J. Q. Tarn et al [19] presented a mathematical formulations for LCT under several loading cases such as torsion, flexion and pressurization. Some other studies have been made under different loading conditions [20], [21]. Theoretical models to predict the mechanical behavior of thick composite tubes were developed by [8]. These models were implemented as an engineering computational tool via Matlab. The behavior of composite tube can be influenced by the Thickness ratio, the lamination angles, the constituent materials, direction of fiber, etc. More generally, the response of tube composite structure depends mainly on the matrix behavior which can be written in terms of the equivalent properties [1], [8]. In reality, the accuracy in predicting the laminated tube behavior is influenced by the stiffness matrix at the macro level of the structure. The stiffness matrix contains sub-matrices which expresses the mechanical couplings that influence the behavior of the tube. The existence of these mechanical couplings depends not only on the shell model but also on the methodology used.

In order to conduct structural designing with accurate results, the designer should take into account more possible mechanical couplings such as: extensionalbending-shearing, extensional-bending, shearingbending, extensional-twisting-shearing, extensionaltwisting, bending-twisting-shearing, and shearing. However, all the above coupling elements do not appear in the laminate constitutive equations based on Kirchhoff-Love (K-L), Reissner-Mindlin, Donnel shell theories or its derivatives used to predict the behavior of the CT by some authors.

In this work, we present an analytical method to study the behavior of laminated composite tube. ABCDE matrix was implemented using Matlab script to compute the strains and stresses distribution fields. Our results were compared by other formulations obtained by K-L and R-M shell models. The influence of new mechanical coupling cited above was clarified. To compute the transverse and normal stresses fields, we proposed to use an original analytical formulation obtained by solving a transverse differential equation. This equation has been proposed initially for isotropic material by [22] and recently solved for anisotropic material by [4]. In fact composite laminates are of anisotropic nature, thus the need to use the theory of anisotropic elasticity. The results obtained by our laminate constitutive relation for composite tube are physically consistent and coherent with literary informations. We have shown that the mechanic couplings cited above is of great influence to the mechanical behavior of LCS when the thickness-ratio increases.

\section{MATHEMATICAL MODELING}

Some two-dimensional shell theories are approximations of real three-dimensional elasticity problems. In fact, equations of 2D shell may be viewed as a simplification of the equation of three dimensional elasticity obtained by eliminating some terms of less order of magnitude with respect to the thickness of the shell $2 \varepsilon, \varepsilon>0$ (the half-thickness is assumed to be small). This simplification is possible by using a middle surface as the reference configuration of the shell and its thickness. Doing so, it is therefore possible to define a system of three-dimensional natural curvilinear coordinates inside the middle surface of shell. 
Moreover, in the shell theory, the three-dimensional system is reduced to a two-dimensional one by deploying a set of simplifying assumptions which are considered and recalled in this paper $[4,23]$ as below: (H1) The material of each constituent layer is linearly elastic. (H2) The laminated consist of number of anisotropic layers of uniform thickness together where each is treated as homogeneous and orthotropic. (H3) For two-dimensional thick shell, the laminate is perfectly bonded i.e. transverse/normal strains are zeros $\left(\epsilon_{\alpha 3}=0, \alpha=1,2,3\right.$ ). (H4) The transverse and normal stresses aren't neglected for geometrically thin shell and geometrically thick shell. (H5) Geometrically twodimensional shell theory is based on the assumption that the ratio of the shell thickness to radius $\left(\chi=\frac{h}{2 R}\right)$ is less than unity.

(H6) Transverse slopes are assumed to be sufficiently small that the linearized curvature expressions are adequate. (H7) Deformations are assumed to be sufficiently small that linearized strain-stress equations may be used.

\section{A. Two dimensional shell model}

One original model of shell theory obtained by applying the limit analysis is the Nzengwa-Tagne (NT) shell model which was developed in 1999. Without any ad hoc assumption on shell deformations or on material texture, authors deduced a two-dimensional model for linear elastic shells from the threedimensional problem of a shell of thickness $2 \varepsilon, \varepsilon>0$ [22].

The body is called shell when there is a surface $S \subset \mathbb{R}^{3}$ and a number $r>0$, which is small compared with the characteristic dimensions of, such that

$$
\text { Let } \quad \Omega=\left\{x \in \mathbb{R}^{3}, \operatorname{dist}(x, S)<r\right\}
$$

(where $\mathrm{S}$ is mid-surface, $\mathrm{h}>0$ is the thickness, and $\boldsymbol{x}=$ $\left(x^{1}, x^{2}\right)$ is the coordinate of $m$ in $S$. The detail of geometry and notation are shown in [4].

We assume the surface $S$ is bounded and sufficiently smooth for all subsequent computations (see Figure 1). Let $\left\{a_{1}, a_{2}, a_{3}\right\}$ and $\left\{a^{1}, a^{2}, a^{3}\right\}$ denote the covariant and contravariant basis of midsurface. Let $\left\{g_{1}, g_{2}, g_{3}\right\}$ and $\left\{g^{1}, g^{2}, g^{3}\right\}$, respectively the covariant and contravariant basis of shell. $g_{\alpha}=\left(\delta_{\alpha}^{\tau}-z b_{\alpha}^{\tau}\right) a_{\tau}=\left(\mu_{\alpha}^{\tau}\right) a_{\tau}, \quad g_{3}=a_{3}, \quad g^{\alpha}=$ $\left(\mu_{\tau}^{\alpha}\right)^{-1} a^{\tau}$

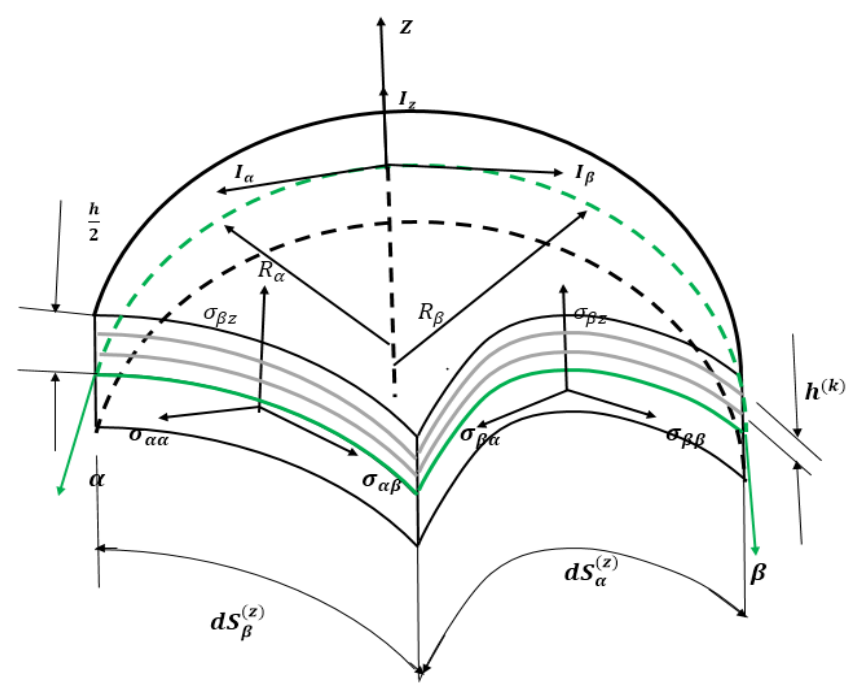

Figure. 1 Laminated shell and notations [4]

N-T's theoretical approach was mathematically and rigorously deduced from three-dimensional linear elastic curvilinear media and through multiple scaling and limit analysis. Moreover it is well known that transverse stresses cannot be neglected as the shell becomes thicker. A field displacement in $g^{i}-$ basis or $a^{i}$ - basis reads:

$u=u_{i}(\boldsymbol{x}, z) g^{i}=\bar{u}_{i}(\boldsymbol{x}, z) a^{i}, u_{\alpha}=\left(\mu_{\alpha}^{\tau}\right) \bar{u}_{\alpha} \quad \bar{u}_{\alpha}=$ $\left(\mu_{\alpha}^{\tau}\right)^{-1} u_{\alpha}$

Then the strain tensor is given by:

$\boldsymbol{\epsilon}_{\alpha \boldsymbol{\beta}}(\boldsymbol{u})=\frac{1}{2}\left(\boldsymbol{u}_{\alpha / \boldsymbol{\beta}}+\boldsymbol{u}_{\boldsymbol{\beta} / \boldsymbol{\alpha}}\right)=\frac{1}{2}\left(\left(\mu_{\alpha}^{\tau}\right)\left(\nabla_{\boldsymbol{\beta}} \bar{u}_{\tau}-\right.\right.$

$\left.\left.\boldsymbol{b}_{\tau \boldsymbol{\beta}} \bar{u}_{3}\right)+\left(\mu_{\beta}^{\tau}\right)\left(\nabla_{\boldsymbol{\beta}} \bar{u}_{\tau}-\boldsymbol{b}_{\boldsymbol{\alpha} \tau} \bar{u}_{3}\right)\right)$

$\boldsymbol{\epsilon}_{\alpha 3}(\boldsymbol{u})=\frac{1}{2}\left(u_{\alpha / 3}+u_{3 / \alpha}\right)=\frac{1}{2}\left(\left(\mu_{\alpha}^{\tau}\right) \bar{u}_{\tau, 3}+\bar{u}_{3, \alpha}+\right.$

$\left.b_{\alpha}^{\tau} \bar{u}_{\tau}\right)$

$\boldsymbol{\epsilon}_{33}(\boldsymbol{u})=\bar{u}_{3,3}$ where $b_{\alpha}^{\tau}=a^{\tau \gamma} b_{\gamma \alpha}$ and $b_{\gamma \alpha}$ denote the curvature tensor components and $a^{\tau \gamma}$ is the contravariant component of metric of the midsurface S. $\boldsymbol{\nabla}$ indicates the covariant derivation in $\Omega$ and $\mathrm{S}$ respectively, while $f_{, \alpha}=$ $\partial f / \partial x^{\alpha}$.

$\epsilon_{i 3}=0$ and, as a consequence, the limit displacement reads:

$u_{\alpha}=\xi_{\alpha}(\boldsymbol{x})-z \theta_{\alpha}(\boldsymbol{x})+z^{2} \psi_{\alpha}(\boldsymbol{x})$,

$u_{3}=\xi_{3}(\boldsymbol{x})$

where $\quad \theta_{\alpha}=\bar{u}_{3, \alpha}+2 b_{\alpha}^{\tau} \bar{u}_{\tau} ; \psi_{\alpha}=b_{\alpha}^{\tau}\left(b_{\alpha}^{\tau} \bar{u}_{\tau}+\theta_{\alpha}\right)$

(6)

The strain tensor is now deduced from N-T shells kinematic $[4,22]$ with respect to plane strain (in view of hypothesis (H3) is given by equation (7) : 


$$
\begin{aligned}
& \boldsymbol{\epsilon}_{\boldsymbol{\alpha} \boldsymbol{\beta}}(\boldsymbol{u})=e_{\boldsymbol{\alpha} \boldsymbol{\beta}}\left(\bar{u}_{\tau}\right)-z K_{\boldsymbol{\alpha} \boldsymbol{\beta}}\left(\bar{u}_{\tau}\right)+ \\
& z^{2} Q_{\boldsymbol{\alpha} \boldsymbol{\beta}}\left(\bar{u}_{\tau}\right) ; \epsilon_{i 3}(u)=0, i=1,2,3
\end{aligned}
$$

Where the tensors associated with arbitrary displacement field $\quad \bar{u}=u_{\tau} a^{\tau} \quad$ on surface. $\boldsymbol{e}=e_{\alpha \beta}(\bar{u}), \quad \boldsymbol{K}=K_{\alpha \beta}(\bar{u})$, and $\boldsymbol{Q}=Q_{\alpha \beta}(\bar{u})$ denote respectively, the membrane deformation tensor, the linearized change of curvature tensor and the linearized change in third fundamental form (or gauss curvature tensor) with respect to shell axes.

$e_{\alpha \beta}\left(\bar{u}_{\tau}\right)=\frac{1}{2}\left(\nabla_{\beta} \bar{u} \cdot a_{\alpha}+\nabla_{\alpha} \bar{u} \cdot a_{\beta}\right)$,

$K_{\alpha \beta}\left(\bar{u}_{\tau}\right)=\left(\nabla_{\alpha \beta} \bar{u}-\Gamma_{\alpha \beta}^{\tau} \nabla_{\alpha} \bar{u}\right) \cdot a_{3}$

$Q_{\alpha \beta}=\frac{1}{2}\left(b_{\alpha}^{\tau} \nabla_{\beta} \theta_{\tau}+b_{\alpha}^{\tau} \nabla_{\beta} \theta_{\tau}\right)$,

Where, $\quad \Gamma_{\alpha \beta}^{\tau}:=\frac{1}{2}\left(a_{\alpha \beta}\right)^{-1}\left(\nabla_{\alpha} a_{\beta \gamma}+\nabla_{\alpha} a_{\alpha \gamma}-\nabla_{\gamma} a_{\alpha \beta}\right)$ designate the Christoffel symbols and $\left(a_{\alpha \beta}\right)^{-1}:=$ $a^{\tau \gamma}$

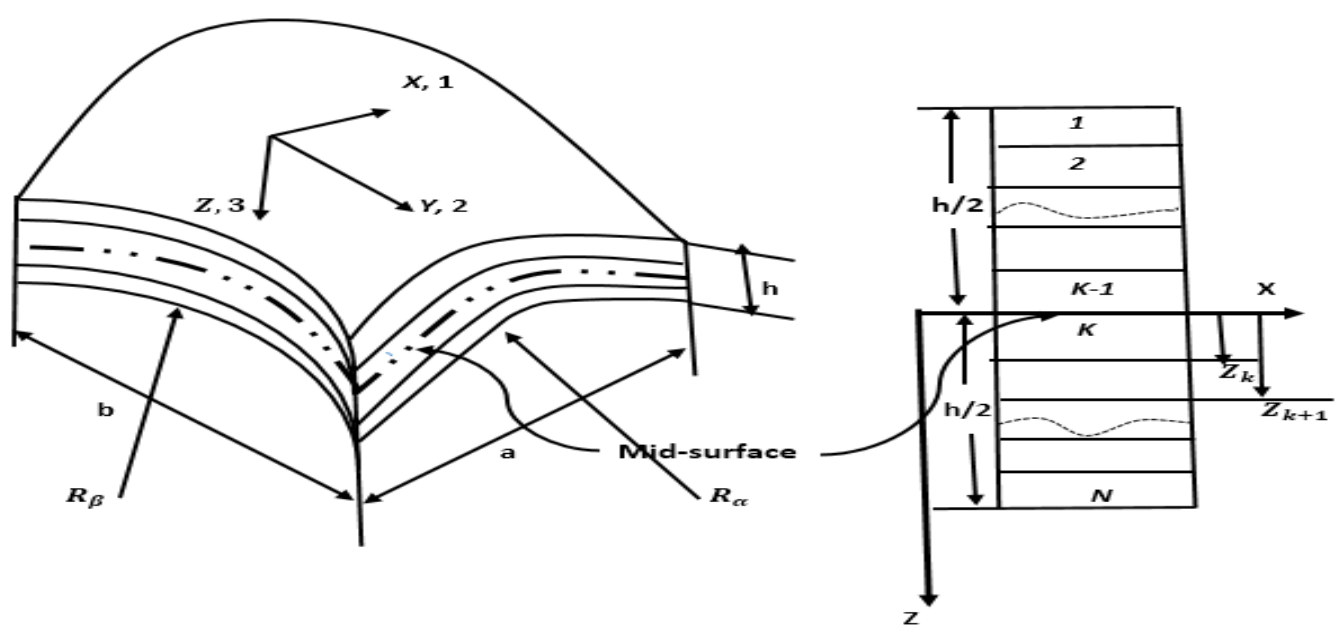

The expressions of these tensors are available in $[4,1,22]$ for spherical and cylindrical shell [1].

The expressions of these tensors are available in $[4,1$, 22] for spherical and cylindrical shell [1]. It is worth noting that the term $\left\{\boldsymbol{Q}_{\boldsymbol{\alpha} \boldsymbol{\beta}}\right\}_{k}$ disappears usually in classical laminated shell models. The fact that it appears here does not mean that it is a second order theory as it may be easily thought. It results from the $\mathrm{N}-\mathrm{T}$ approach which suppresses the use of a correction factor.

Figure 2. Geometry of shell, and location of layer in the composite shell structure [4]

In view of hypotheses (H1) and (H4) the strain-stress relationship can be written by equation (13) following:

$$
\begin{aligned}
& \left\{\sigma_{\alpha \beta}\right\}_{k}=[\bar{Q}]_{k}\left\{e_{\alpha \beta}\right\}_{k}-[\bar{Q}]_{k} z_{k}\left\{K_{\alpha \beta}\right\}_{k}+ \\
& {[\bar{Q}]_{k} z_{k}{ }^{2}\left\{Q_{\alpha \beta}\right\}_{k}}
\end{aligned}
$$

In this equation, the strains are given at a $z_{k}$ location where the stresses are required (see Figure 3); and $[\bar{Q}]_{k}$ is the stiffness matrix with respect to shell coordinates. It is obtained by transforming the stiffness matrix $\mathrm{Q}$ in the principal material coordinates $(x, y, z)$ to shell coordinates (1-2-3) using coordinate transformation matrix given by the relation $[23,1,24]$

$[\bar{Q}]_{k}=\left[T_{\sigma}\right]^{-1}[Q]_{k}[R]\left[T_{\sigma}\right][R]^{-1}$.

where $\left[T_{\sigma}\right]$ is the transformation matrix; $[R]$ is the Reuter matrix defined respectively by:

$$
T_{\sigma}=\left(\begin{array}{ccc}
c^{2} & s^{2} & 2 c s \\
s^{2} & c^{2} & -2 c s \\
-c s & c s & c^{2}-s^{2}
\end{array}\right) \text { and } R\left(\begin{array}{lll}
1 & 0 & 0 \\
0 & 1 & 0 \\
0 & 0 & 2
\end{array}\right)
$$

For N-T shell, transverse shear stresses $\left(\sigma_{13}, \sigma_{23}\right)_{k}$ and normal $\left(\boldsymbol{\sigma}_{33}\right)_{k}$ in each layer $k$ can be predictable accurately by solutions of differential equations presented here recently developed [4].

Consider a shell of thickness h clamped on a part of its border $\Gamma_{0}$, subjected to volume forces $f^{\alpha}, f^{3}$ and to surface forces $\bar{h}^{\alpha}$ and $\bar{h}^{3}$ on the rest of its border $\Gamma^{1}$. Suppose the forces are sufficiently smooth; then the transverse stresses $\sigma^{\alpha 3}$ and normal stresses $\sigma^{33}$ are solutions to the differential equations [22]:

$$
\frac{\partial \sigma^{\alpha 3}}{\partial z}+2 \Gamma_{\lambda 3}^{\alpha} \sigma^{\alpha 3}+\Gamma_{\lambda 3}^{\lambda} \sigma^{\alpha 3}=-\left(\sigma_{, \beta}^{\alpha \beta}+\Gamma_{\beta \lambda}^{\beta} \sigma^{\lambda 3}-\right.
$$
$\left.f^{\alpha}\right)$, 
$\sigma^{\alpha 3}\left(-\frac{h}{2}\right)=-\bar{h}_{-}^{\alpha}=0, \quad \sigma^{\alpha 3}\left(+\frac{h}{2}\right)=\bar{h}_{+}^{\alpha}=0$,

with $f^{\alpha} \in L^{2}(\Omega), H^{1}\left(-\frac{h}{2}, \frac{h}{2}, H^{-1}(S)\right)$.

$\frac{\partial \sigma^{33}}{\partial z}+\Gamma_{\alpha 3}^{\alpha} \sigma^{33}=-\left(\sigma_{, \alpha}^{3 \alpha}+\Gamma_{\alpha \lambda}^{3} \sigma^{\lambda \alpha}+\Gamma_{\lambda 3}^{\lambda} \sigma^{\alpha 3}-f^{\alpha}\right)$

$\sigma^{33}\left(-\frac{h}{2}\right)=-\bar{h}_{-}^{3}=0, \sigma^{33}\left(+\frac{h}{2}\right)=\bar{h}_{+}^{3}=0$,

$$
f^{\alpha} \in H^{1}(\Omega), H^{2}\left(-\frac{h}{2}, \frac{h}{2}, H^{-2}(S)\right) \text {. }
$$

It is possible to obtain transverse strain and stress of laminate composite shell using directly three dimensional constitutive relation obtained by 3D shell model. (see for instance [4]). This shell model is not presented here.

In the following subsection we present a new general laminate constitutive equations.

\section{B. The Shell Model Based 2D Laminate Constitutive Relation}

We can find them using Equation (6). We assume that we know the applied force $\mathrm{N}=\left(\mathrm{N}_{\alpha}, \mathrm{N}_{\beta}, \mathrm{N}_{\alpha \beta}\right)$, the Gauss bending and twisting moments $\mathrm{M}=$ $\left(M_{\alpha}, M_{\beta}, M_{\alpha \beta}\right), \quad$ and $M^{*}=\left(M_{\alpha}^{*}, M_{\beta}^{*}, M_{\alpha \beta}^{*}\right)$ respectively. Let $\mathbf{N}=\mathrm{N}_{\alpha \beta} \mathrm{i}_{\alpha} \otimes \mathrm{i}_{\beta}, \mathbf{M}=$ $M_{\alpha \beta} i_{\alpha} \otimes i_{\beta}, \quad \mathbf{M}^{*}=M_{\alpha \beta}^{*} i_{\alpha} \otimes i_{\beta} \quad$ where $i_{\alpha} \otimes i_{\beta}$ is the projector. Using this projector Therefore, the resultant stresses and moment are defined as integral of stresses through the thickness of laminated shell, while using the Lamé parameters $A_{\alpha}$ and $A_{\beta}$, and radius of shell $R_{\alpha}$ and $R_{\beta}$, see [25]. The Laminate constitutive relation is given by:

$$
\left(\begin{array}{l}
\boldsymbol{N} \\
\boldsymbol{M} \\
\boldsymbol{M}^{*}
\end{array}\right)=\left(\begin{array}{ccc}
A & -B & C \\
-B & C & -D \\
C & -D & E
\end{array}\right)\left(\begin{array}{l}
\boldsymbol{e} \\
\boldsymbol{K} \\
\boldsymbol{Q}
\end{array}\right)
$$

The sub-matrices A,B,C,D,E, are defined by:

$$
\begin{aligned}
& \left(\mathrm{A}_{\mathrm{ij}}, \mathrm{B}_{\mathrm{ij}}, \mathrm{C}_{\mathrm{ij}}, \mathrm{D}_{\mathrm{ij}}, \mathrm{E}_{\mathrm{ij}}\right)= \\
& \quad \sum_{\mathrm{k}=1}^{\mathrm{Nb}} \int_{\mathrm{h}_{\mathrm{k}-1}}^{\mathrm{h}_{\mathrm{k}}}\left(1, \mathrm{z}, \mathrm{z}^{2}, \mathrm{z}^{3}, \mathrm{z}^{4}\right)\left[\overline{\mathrm{Q}}_{\mathrm{ij}}\right]_{\mathrm{k}} \mathrm{dz}, \mathrm{i}, \mathrm{j}=1,2,6 .
\end{aligned}
$$

$N b$ denotes the layers number, $z$ and $h_{k}$ define the position of the $k^{\text {th }}$ layer from the mid-plane of the composite laminate ( Fig. 3).

Here $A, B, C, D$ and $E$ sub-matrices are calculated by using the lamination theory with axis parallel theorem and are known in CLST as the extensional-shearing mechanical coupling $\left(A_{16}\right.$ and $\left.A_{26}\right)$, extensionalbending mechanical coupling $\left(B_{11}, B_{12}, B_{22}\right)$, extensional-bending-shearing coupling $\left(C_{11}, C_{12}, C_{22}\right)$, extensional-twisting-Gausss mechanical coupling $\left(C_{16}\right.$ and $\left.C_{26}\right)$, shearing mechanical coupling $\left(D_{11}, D_{12}, D_{22}\right)$, Gauss bending-twisting-shearing mechanical coupling $\left(D_{16}\right.$ and $\left.D_{26}\right)$ and shearing stiffness mechanical coupling $\left(E_{16}\right.$ and $\left.E_{26}\right)$. The last four among the above couplings are the additional mechanical couplings due to the presence of the Gaussian tensor in the Strain-stress relation (9).

We can find $\boldsymbol{e}, \boldsymbol{K}$, and $\boldsymbol{Q}$ by solving the nine simultaneous equations obtained by inverse calculation and given by [1]:

$\left(\begin{array}{l}\boldsymbol{e} \\ \boldsymbol{K} \\ \boldsymbol{Q}\end{array}\right)=\left(\begin{array}{lll}A^{1} & B^{1} & C^{1} \\ D^{1} & E^{1} & F^{1} \\ G^{1} & H^{1} & I^{1}\end{array}\right)\left(\begin{array}{c}\boldsymbol{N} \\ \boldsymbol{M} \\ \boldsymbol{M}^{*}\end{array}\right)$,

where $A^{1}, B^{1}, C^{1}, D^{1}, E^{1}, F^{1}, G^{1}, H^{1}, I^{1}$ are given by [24].

C. Interlaminar/Transverse Stresses from the TwoDimensional Anisotropic Shell.

Predicting the interlaminar stresses are of particular interest in real application. We recall that some two dimensional LCS models based on K-L, R-M, Donnel shell models or its derivatives shell model are not capable to predict with accuracy some local effects as interlaminar stress distribution between layer.

Certain of these models utilize plane stress assumptions which are not always suitable for layered composite, since some capital informations about the transverse stresses are lost. Moreover some analytical formulations of transverse stresses have not been mathematically established.

It is well-known that the transverse stresses can not be neglected when the LCS becomes thicker. The LCS models based on R-M theory for instance use a shear correction factor to determine the transverse stresses but fails to give accuracy results. Others technique to find the transverse shear stresses without shear correction factor consist of using stress recovery from the equation equilibrium (body forces excluded). The two-dimensional models capable to predict by equivalent single layer the transverse stresses with accuracy are generally poor or non-existent. To determine all the transverse stresses components, a newly analytical formulation developed by Arno Ngatcha et al [23]:

$$
\begin{aligned}
& \left(\sigma_{13}\right)_{k}=-\left[N_{0}-N_{1} h_{k}+N_{2} h_{k}^{2}\right] \exp (-\tau(z- \\
& \left.\left.h_{k}\right)\right)+\left[N_{0}-N_{1} h_{k-1}+N_{2} h_{k-1}^{2}\right] \exp \left(-\tau\left(z-h_{k-1}\right)\right) \\
& \left(\sigma_{23}\right)_{k}=\frac{1}{C-\tau}\left[\left(\bar{\delta}_{1}+\bar{\delta}_{2} h_{k}+\bar{\delta}_{3} h_{k}^{2}\right)+\left(\bar{\delta}_{1}+\right.\right. \\
& \left.\bar{\delta}_{2} h_{k-1}+\bar{\delta}_{3} h_{k-1}^{2}\right) \exp \left(-\tau\left(h_{k}-\right.\right. \\
& \left.\left.\left.h_{k-1}\right)\right)\right] \exp \left(-C\left(z-h_{k}\right)\right) \\
& \left(\sigma_{33}\right)_{k}=\frac{1}{C-\tau}\left[\left(\bar{\delta}_{1}+\bar{\delta}_{2} h_{k}+\bar{\delta}_{3} h_{k}^{2}\right)+\left(\bar{\delta}_{1}+\right.\right. \\
& \left.\bar{\delta}_{2} h_{k-1}+\bar{\delta}_{3} h_{k-1}^{2}\right) \exp \left(-\tau\left(h_{k}-\right.\right.
\end{aligned}
$$


$\left.\left.\left.h_{k-1}\right)\right)\right] \exp \left(-C\left(z-h_{k}\right)\right)+\frac{-1}{C-\tau}\left[\left(\bar{\delta}_{1}+\bar{\delta}_{2} h_{k}+\right.\right.$ $\left.\bar{\delta}_{3} h_{k}^{2}\right)+\left(\bar{\delta}_{1}+\bar{\delta}_{2} h_{k-1}+\bar{\delta}_{3} h_{k-1}^{2}\right) \exp \left(-\tau\left(h_{k}-\right.\right.$

$\left.\left.\left.h_{k-1}\right)\right)\right] \exp \left(-C\left(z-h_{k-1}\right)\right)$;

Where $n_{i}, \bar{\delta}_{i}, N_{i}, \mathrm{i}=1,2,3, \quad \tau, C, B(z)$, are the values and functions available in [4].

D. Appropriate Laminate Stiffness matrix for a Uniform Cylindrical Tube.

We determined the stiffness matrices of a composite tube or cylinder using the approach proposed by [26], and [27]. We consider an infinitesimal plate section of tube laminate which has its axis $x-y-z$ and is inclined at an angle $\theta$ with respect to the composite tube axis. This section is rotated about $\mathrm{z}(\mathrm{z}=R \cos \theta)$ to position it parallel to the $\mathrm{x}$-axis (Fig. 4). The stiffness of the plate

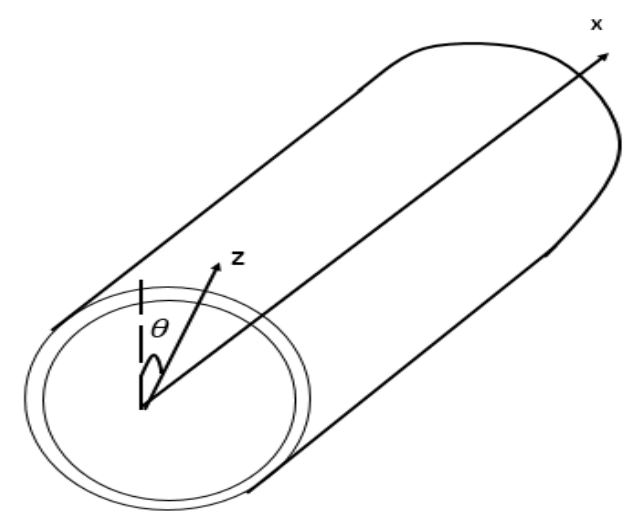

calculated by lamination theory is translated to the $\mathrm{x}$ axis according to parallel axis theorem [28].

We considered the uniform tube with circular crosssections $R_{0}$, and $\mathrm{L}$ respectively for the outer and inner radii. The length of the cylindrical composite is $\mathrm{L}$. The length of the tube is sufficiently high than that of its radii. Hence the tube is considered as long. Taking into account the strain and stress transformation matrices $\left[T_{\varepsilon}\right]$ and $\left[T_{\sigma}\right],\left[T_{\varepsilon}\right]_{x}=\left[T_{\sigma}\right]_{x}=\left(\begin{array}{ccc}1 & 0 & 0 \\ 0 & m^{2} & 0 \\ 0 & 0 & m\end{array}\right)$ where $m=\cos \theta$, hence, reduced stiffness matrices after $Z$ and $X$ rotation will be given by:

$\left[Q^{\prime}\right]=\left[T_{\sigma}\right]_{z}[Q]\left[T_{\varepsilon}\right]_{z},[\bar{Q}]=\left[T_{\sigma}\right]_{x}\left[Q^{\prime}\right]\left[T_{\varepsilon}\right]_{x}$,

Where

$\left[T_{\sigma}\right]_{z}=T_{\sigma}$ and $\left[T_{\varepsilon}\right]_{z}=T_{\varepsilon}$.

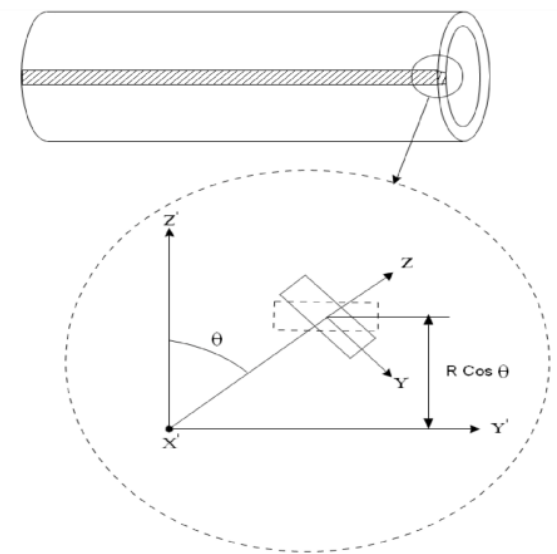

Figure 3. Uniform cylindrical composite tube and notations.

The overall stiffness of the composite tube (or cylinder) is thus obtained by integrating over the entire $\theta$ domain. The corresponding stiffness matrix elements $[\bar{A}],[\bar{B}],[\bar{C}],[\bar{D}]$ and $[\bar{E}]$ of the tube can be written as: $[\bar{A}]=\int_{0}^{2 \pi}\left[A^{\prime}\right] \operatorname{Rd} \theta, \quad[\bar{B}]=\int_{0}^{2 \pi}\left[B^{\prime}\right] \operatorname{Rd} \theta,[\bar{C}]=[\bar{D}]=$ $\int_{0}^{2 \pi}\left[D^{\prime}\right] R d \theta,[\bar{E}]=\int_{0}^{2 \pi}\left[E^{\prime}\right] R d \theta$.

\section{Where}

$$
\begin{aligned}
& {\left[A^{\prime}\right]=[A] ;\left[B^{\prime}\right]=[B]+R \cos (\theta)[A] ;\left[C^{\prime}\right]=[C]+} \\
& 2 R \cos (\theta)[C]+(R \cos (\theta))^{2}[C] ; \\
& {\left[D^{\prime}\right]=[D]+3 R \cos (\theta)[C]+3(R \cos (\theta))^{2}[B]+} \\
& (R \cos (\theta))^{3}[A] ; \\
& {\left[E^{\prime}\right]=[E]+4 R \cos (\theta)[D]+6(R \cos (\theta))^{2}[C]+} \\
& 4(R \cos (\theta))^{3}[B]+(R \cos (\theta))^{4}[A] .
\end{aligned}
$$

Note that those stiffness matrices are in terms of $R$ where $R$ is the mid-thickness radius of the circular tube. $R=R_{0}-0.5 N b t_{k}$ where $N b$ is the number of layers and $t_{k}$ is the ply thickness.

In the case of laminated composite tubes (LCT), the constitutive relation is obtained through inverse calculation by the following Laminate constitutive equation for laminated uniform cylinder tube:

$$
\left(\begin{array}{c}
\boldsymbol{N} \\
\boldsymbol{M} \\
\boldsymbol{M}^{*}
\end{array}\right)=\left(\begin{array}{ccc}
\bar{A} & -\bar{B} & \bar{C} \\
-\bar{B} & \bar{C} & \overline{-D} \\
\bar{C} & -\bar{D} & \bar{E}
\end{array}\right)\left(\begin{array}{l}
\boldsymbol{e} \\
\boldsymbol{K} \\
\boldsymbol{Q}
\end{array}\right)
$$

More generally, we obtained the stiffness matrices by following the procedure described in the flowchart given bellow: 


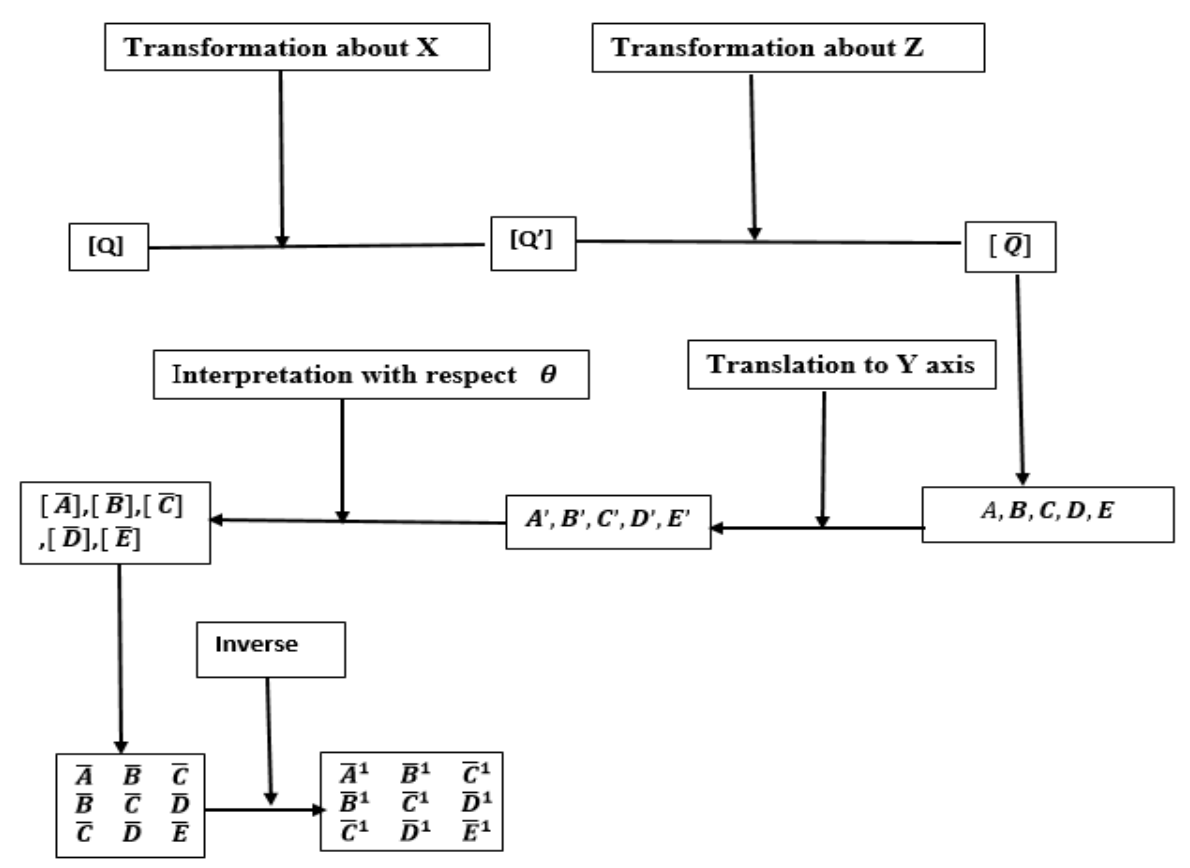

Figure 4. Flowchart for analytical modelling stiffness matrices of laminate cylindrical tube

\section{NUMERICAL RESULTS AND DISCUSSIONS}

In this section we developed some applications which will help to analyze laminated composite cylindrical tubes. First, we obtained solutions of the local stresses, and strains for each layer at the top, middle and bottom. We compared results obtained using classical laminated shell theory containing ABD matrix based on K-L shell model, classical FSDT containing ABDF matrix based on R-M shell model, and our formulation (ABCDE matrix) obtained by N-T shell model.

Matlab computational tool was used to compute the stresses and strains distribution fields in laminated tube with sacking sequence equal to $\left[0 \% / 30^{\circ} /-45^{\circ}\right]$. The circular tube has a mid-thickness radius equal to $R=$ $R_{0}-0.5 \mathrm{Nbt}_{k}$. The mechanical properties of the materials used to fabricate the composite tube are given in Table1.

The composite tube is analyzed under different static loading conditions. The results are presented in Table 2-4 and graphically in Fig. 5 - Fig. 8.

The results obtained by using our LCE method are compared with those obtained by using ABD in CLST and laminate shell constitutive equations model (ABDG) according to FSDT of R-M. 
Table 1. 2D Material properties, limits and loading conditions for graphite/ Epoxy Composite

\begin{tabular}{|c|c|c|c|c|c|c|}
\hline \multirow{2}{*}{$\begin{array}{c}\begin{array}{l}\text { Material } \\
\text { properties }\end{array} \\
E_{1}(G p a)\end{array}$} & \multirow{2}{*}{$\begin{array}{l}\begin{array}{l}\text { Carbon } \\
\text { AS4/PEKK }\end{array} \\
140\end{array}$} & \multirow{2}{*}{$\begin{array}{l}\begin{array}{l}\text { Graphite/ } \\
\text { Epoxy }\end{array} \\
181\end{array}$} & \multirow{2}{*}{$\begin{array}{l}\text { Car/Ep } \\
\text { (IM6/S1081) } \\
177\end{array}$} & \multicolumn{3}{|c|}{ loading } \\
\hline & & & & $N$ & $M$ & $M^{*}$ \\
\hline$E_{2}(G p a)$ & 10 & 10.3 & 10.8 & 1000 & 0 & 0 \\
\hline$G_{12}(G p a)$ & 5.56 & 7.17 & 7.6 & 1000 & 0 & 0 \\
\hline $\begin{array}{l}v_{12} \\
v_{12}\end{array}$ & 0.31 & 0.28 & 0.27 & 0 & 0 & 0 \\
\hline$G_{13}(G p a)$ & 5.56 & & & & & \\
\hline$G_{23}(G p a)$ & 5.56 & & & & & \\
\hline
\end{tabular}

\section{A. Laminated Shell Plate Analysis}

In this example Matlab tools is used to analyze the behavior of classical thin shell configuration. Here we assumed that the transverse slopes are sufficiently small that the linearized curvature expressions are adequate. This test was conducted by [29], [5] for the same material (graphite/epoxy) of which characteristics are given in table. 1. The results obtained by Matlab script code are compared to those proposed by [5], [29]. The influence of thickness ratio is not taken into account in this case (Assumption of plate shell). The shell is analyzed under extensional loading. The maximum local stresses and the minimum local strain are presented in Table. 2. We observed a divergence due to the contribution of new mechanical couplings in the rigidity matrix $\mathrm{ABCDE}$. It seems that our method is not suitable to predict the behavior of flat composite plate.

Table 2. Local Strains/ stresses of graphite/epoxy with ABD-matrix and ABCDE-matrix at different layers with different orientations.

\begin{tabular}{|c|c|c|c|c|c|c|c|}
\hline \multicolumn{2}{|c|}{ Orientation $\left(\theta^{o}\right)$} & \multicolumn{2}{|l|}{$0^{\circ}$} & \multicolumn{2}{|l|}{$30^{\circ}$} & \multicolumn{2}{|c|}{$-45^{\circ}$} \\
\hline & & $\begin{array}{l}\text { ABD } \\
\text { CLT [5] [29] }\end{array}$ & $\begin{array}{l}\text { Present } \\
\text { LCE }\end{array}$ & $\begin{array}{l}\text { ABD } \\
\text { CLT [5] [29] }\end{array}$ & $\begin{array}{l}\text { Present } \\
\text { LCE }\end{array}$ & $\begin{array}{l}\text { ABD } \\
\text { CLT [5] [29] }\end{array}$ & $\begin{array}{l}\text { Present } \\
\text { LCE }\end{array}$ \\
\hline $\begin{array}{l}\text { Minimum } \\
\text { Strains }(\mathrm{mm})\end{array}$ & $\begin{array}{l}\epsilon_{11} \\
\epsilon_{22} \\
\epsilon_{12}\end{array}$ & $\begin{array}{l}0.0001 \\
0.0043 \\
-0.0038\end{array}$ & $\begin{array}{l}-0.000135 \\
-0.00184 \\
-0.00287\end{array}$ & $\begin{array}{l}0.0005 \\
0.0020 \\
0.0021\end{array}$ & $\begin{array}{l}0.0007 \\
0.0038 \\
0.0034\end{array}$ & $\begin{array}{c}-0.0004 \\
0.0017 \\
-0.0023\end{array}$ & $\begin{array}{l}-0.002243 \\
-0.00236 \\
-0.00442\end{array}$ \\
\hline $\begin{array}{l}\text { Maximum } \\
\text { Stresses } \\
\left(\mathrm{N} / \mathrm{mm}^{2}\right)\end{array}$ & $\begin{array}{l}\sigma_{11} \\
\sigma_{22} \\
\sigma_{12}\end{array}$ & $\begin{array}{l}55.76 \\
61.87 \\
-12.80\end{array}$ & $\begin{array}{l}55.9379 \\
55.3591 \\
-13.319\end{array}$ & $\begin{array}{l}200.745 \\
43.4817 \\
18.9030\end{array}$ & $\begin{array}{l}204.136 \\
55.549 \\
30.253\end{array}$ & $\begin{array}{c}258.576 \\
21.231 \\
-3.5333\end{array}$ & $\begin{array}{c}512.0146 \\
27.1901 \\
26.0128\end{array}$ \\
\hline
\end{tabular}

\section{B. Thin Cylindrical Uniform Laminated Tube.}

Table. 3 compares the local strains and local stresses between our analytical formulation which uses ABCDE matrix and the classical formulation which leads to ABD matrix. The convergence of both formulations is excellent. We observe in these results that the membrane deformation and stresses are the same. The additional mechanical couplings do not have any influence in the behavior of tube. $\mathrm{E}$ and $\mathrm{D}$ disappear in the rigidity matrix $\mathrm{ABCDE}$. In this case $\mathrm{ABCDE}, \mathrm{ABD}$ ABDG have same contribution. Thus for geometrically thin shell, our formulation coincides with those used in CLST. This assertion is verified in Table 3 and Fig. 5. where both approach converge very well. Assumptions made above in our model are reasonable and correct. 
Table 3. Local Strains/ stresses of graphite/epoxy uniform cylinder tube with the ratio $\chi=0.099$.

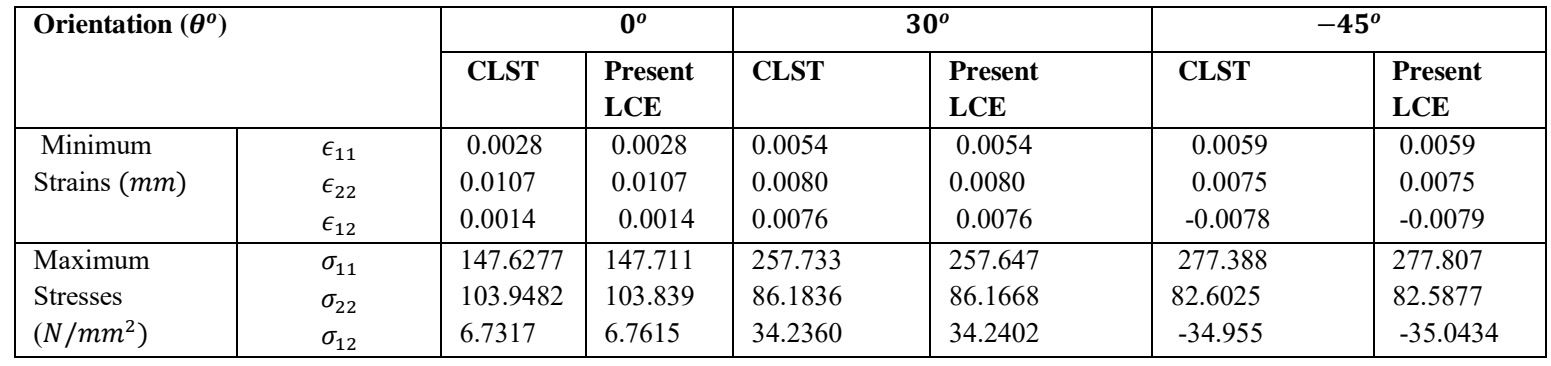

\section{Thick Cylindrical Uniform Laminated Tube.}

Table 4. Comparison of Local Strains and local stresses of graphite/epoxy uniform cylinder tube with the thickness ratio $\chi=0.15$ obtained using Reissner-Mindlin-based formulation (Eq. 29) and the present formulation.

\begin{tabular}{|c|c|c|c|c|c|c|c|}
\hline \multicolumn{2}{|c|}{ Orientation $\left(\theta^{o}\right)$} & \multicolumn{2}{|c|}{$\mathbf{0}^{\circ}$} & \multicolumn{2}{|c|}{$30^{\circ}$} & \multicolumn{2}{|c|}{$-45^{o}$} \\
\hline & & $\begin{array}{c}\text { LCE using } \\
\text { R-M }\end{array}$ & $\begin{array}{l}\text { Present } \\
\text { LCE }\end{array}$ & $\begin{array}{l}\text { LCE using } \\
\text { R-M }\end{array}$ & $\begin{array}{l}\text { Present } \\
\text { LCE }\end{array}$ & $\begin{array}{l}\text { LCE using } \\
\text { R-M }\end{array}$ & $\begin{array}{l}\text { Present } \\
\text { LCE }\end{array}$ \\
\hline $\begin{array}{l}\text { Minimum } \\
\text { Strains }(\mathrm{mm})\end{array}$ & $\begin{array}{l}\epsilon_{11} \\
\epsilon_{22} \\
\epsilon_{12}\end{array}$ & $\begin{array}{l}0.0009 \\
0.0036 \\
0.0005\end{array}$ & $\begin{array}{l}0.0010 \\
0.0036 \\
0.0004\end{array}$ & $\begin{array}{l}0.0018 \\
0.0027 \\
0.0025\end{array}$ & $\begin{array}{l}0.0018 \\
0.0028 \\
0.0026\end{array}$ & $\begin{array}{l}0.0020 \\
0.0025 \\
-0.0026\end{array}$ & $\begin{array}{l}0.0021 \\
0.0025 \\
-0.0027\end{array}$ \\
\hline $\begin{array}{l}\text { Maximum } \\
\text { Stresses } \\
\left(\mathrm{N} / \mathrm{mm}^{2}\right)\end{array}$ & $\begin{array}{l}\sigma_{11} \\
\sigma_{22} \\
\sigma_{12}\end{array}$ & $\begin{array}{l}49.2092 \\
34.6494 \\
2.2439\end{array}$ & $\begin{array}{l}51.360 \\
35.6374 \\
2.1961\end{array}$ & $\begin{array}{c}85.9112 \\
28.7279 \\
11.4120\end{array}$ & $\begin{array}{c}87.0844 \\
30.1208 \\
11.5685\end{array}$ & $\begin{array}{c}92.462 \\
27.5342 \\
-11.652\end{array}$ & $\begin{array}{c}99.194 \\
28.124 \\
-12.126\end{array}$ \\
\hline
\end{tabular}

Note that in this test, $h$ is constant while the radius varies with the ratio $\chi$. The local strains and stresses are influenced by the contribution of additional mechanical couplings, because $E, D$ do not disappear in the rigidity matrix $A B C D E$. This effect is due to the increase of the thickness ratio $\chi=0.15$. The high similarity between both R-M based formulation and the current model is observed in table 4. Thus our formulation is able to compute local stresses and strains of thin and moderately thick tube with very good accuracy.

\section{Stresses Analysis in LCT.}

In this section, we have used the graphite/epoxy mechanical characteristics to perform the computation.
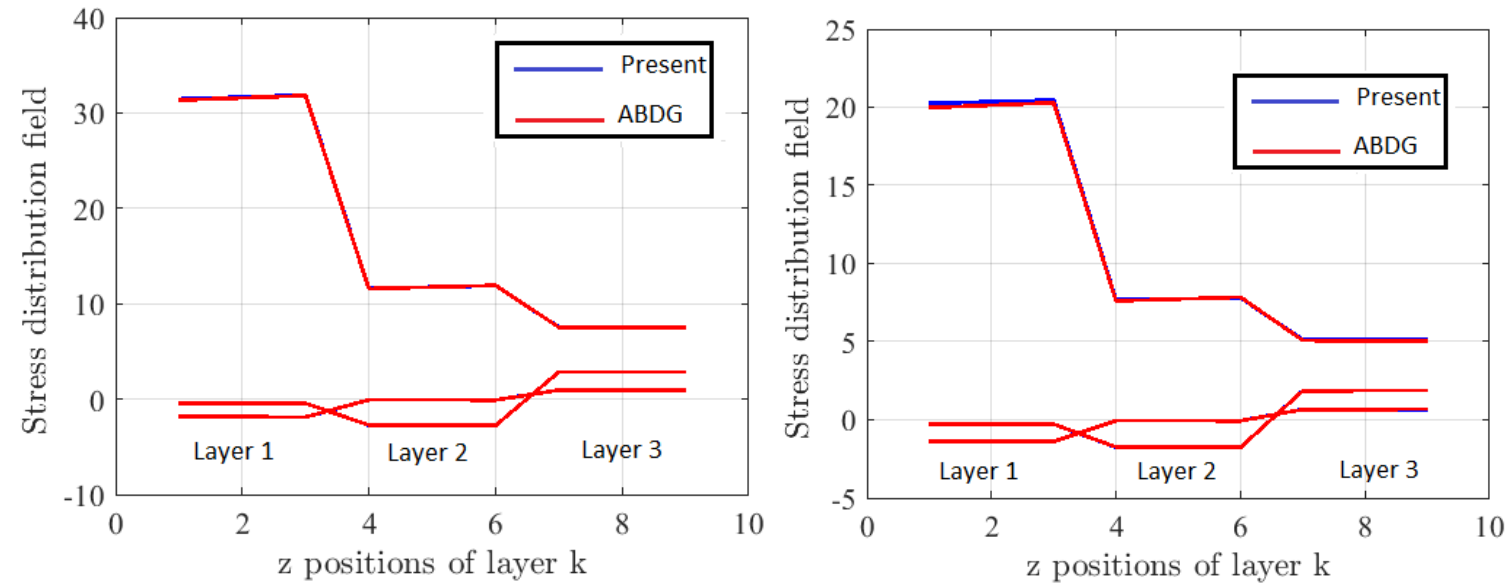

Figure 5: Stresses distribution, left for $\chi=0.075$, right for $\chi=\frac{h}{2 R}=0.1$. 

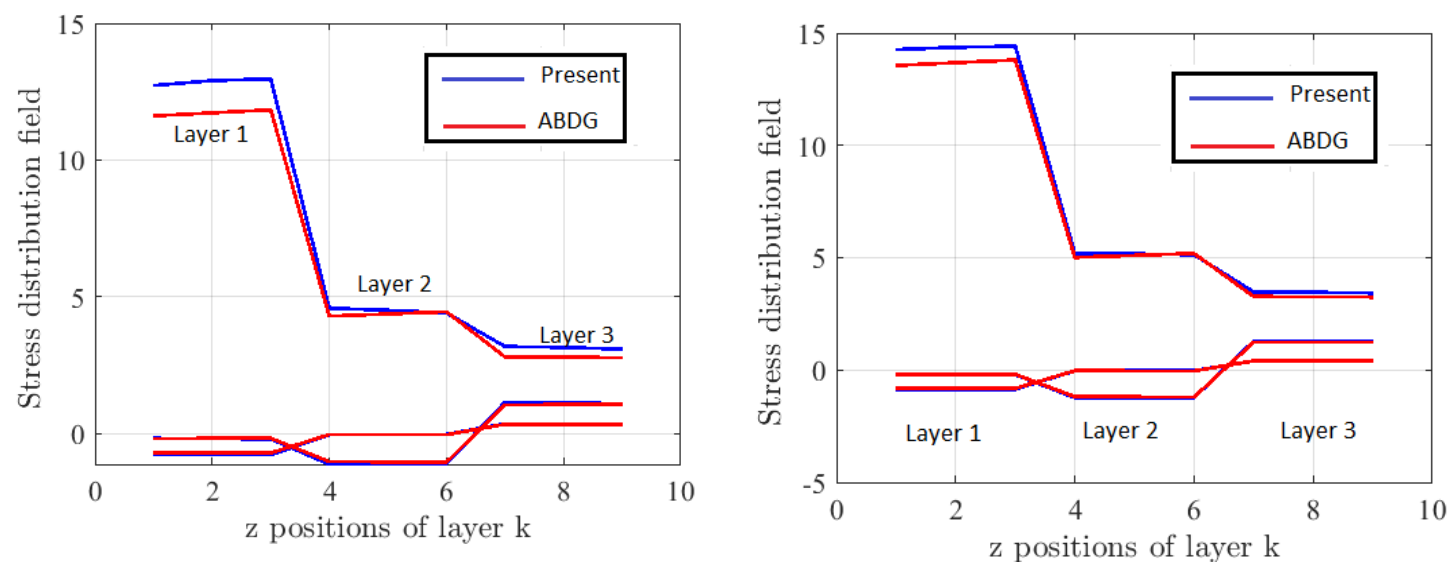

Figure. 6: Stress distribution left for $\chi=0.1765$ and right for $\chi=0.1429$

We have used in the following range of ratios: $0.05 \leq$ $\chi \leq 0.18$ in these tests because they belong to both thin and thick laminated shell thickness ranges. Important remark is that $\chi=\chi(h)$ i.e. the radius of tube is constant. All plots are presented below. Classical rigidity matrix $\mathrm{ABD}$ and that presented in this work (ABCDE-matrix) are implemented analytically using some MATLAB scripts. The result are plotted for some different ratio and results are shown in figure 5 and 6 . We can see that $\chi$ ratio influences considerably the mechanical behavior of the LCST. In fact when $\chi<0.1$, the distribution of stresses and strains of tube is the same. Both plots overlap perfectly.

When $\chi>0.1$, the distribution of stresses are not the same (Figures 6). We can see that the two Laminate constitutive equations diverged [12]. We believe that our model is more accurate because it contains more couples deformation as opposed the RM one. Moreover, it was not deduced by imposing a correction factor.

\section{E. Strain Analysis in LCT.}

In this example Matlab tools is used to analyze the behavior of classical moderately thick shell configuration. 

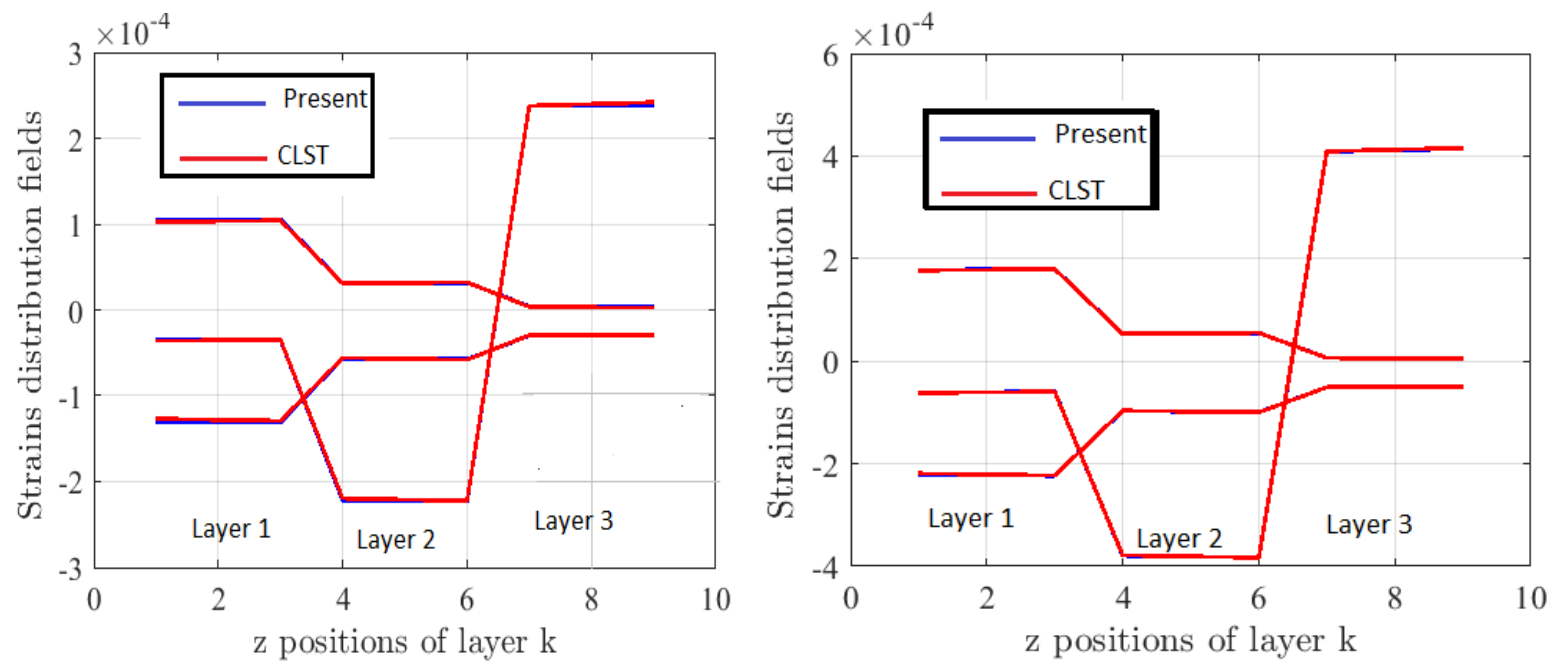

Figure 7: Strains distribution in laminated tube left for $\chi=\frac{h}{2 R}=0.099$ and right at ratio $\chi=\frac{h}{2 R}=0.85$, the Car/Ep (IM6/S1081) has been used here.

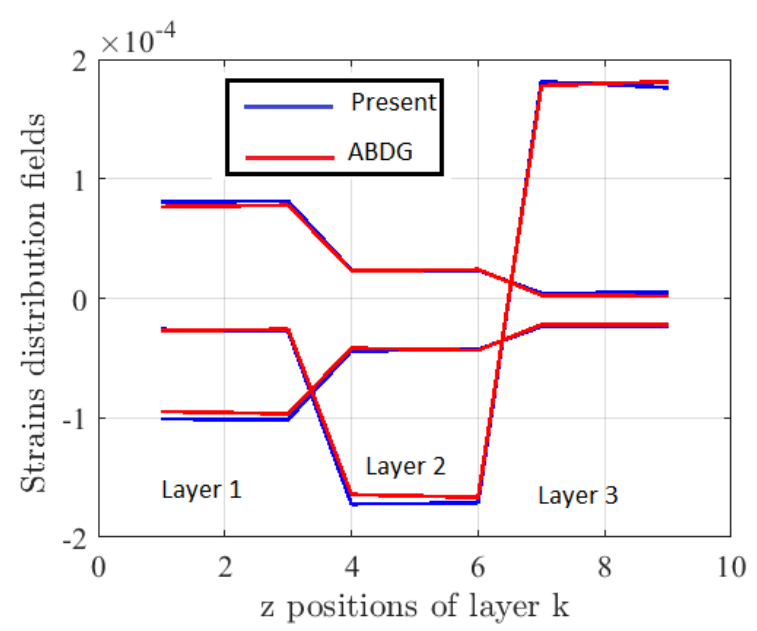

Figure 8: Strains distribution in laminated tube, left (IM6/S1081) has been used here.

The results of the transverse stresses are presented in table 5 below without using a correction factor which is often needed in the case of Reissner-Mindlin shell and other types of models. Those transverse stresses could not be obtained using the ABD matrix. Fig. 7 and 8 shows the strain distribution fields for a wide range of $\chi$ which are 0.099 (Fig. 7), 0.85 (Fig. 7), 0.1429 (Fig. 8), and 0.1765 (Fig. 8). The distribution fields across the tube perfectly overlapped for the two first values of $\chi$ above which are less than 0.1 . For $\chi=$

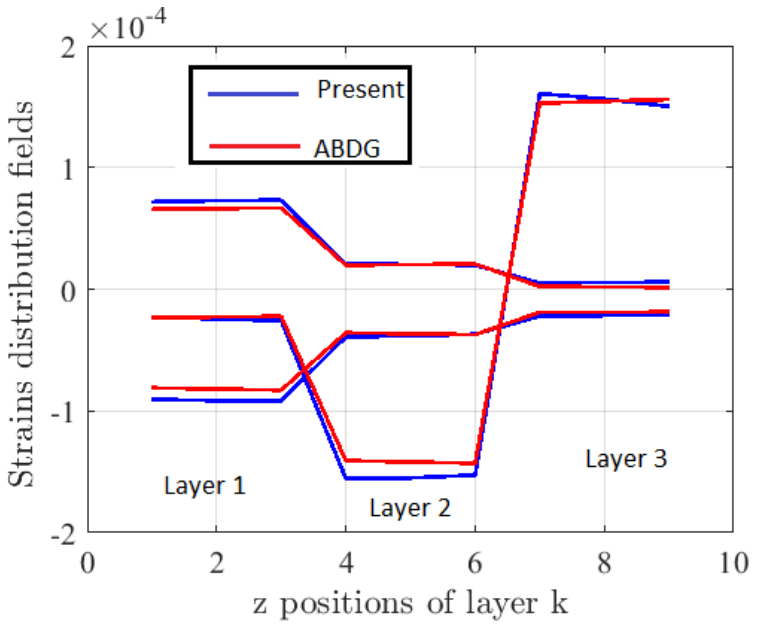

$\chi=\frac{h}{2 R}=0.1429$ and right $\quad \chi=\frac{h}{2 R}=0.1765$, the $\mathrm{Car} / \mathrm{Ep}$ 0.14 and 0.18 respectively, a shift was observed between the two curves in each figure (Fig.8). The shift increased with the value of $\chi$. We believe that this discrepancy is due to the contribution of additional mechanical couplings in our model. A more detailed model which is accurate for thin tube is likely to also show better results in thick tube. Nevertheless, deriving a 3D version of our model is also highly advisable. 
Table 5. Transverse stresses of graphite/epoxy tube.

\begin{tabular}{|l|l|c|c|l|}
\hline \multicolumn{2}{|l|}{ Angle $\left(\boldsymbol{\theta}^{\boldsymbol{o}}\right)$} & 0 & 30 & -45 \\
& & & \\
\hline Max & $\boldsymbol{\sigma}_{13}$ & -0.000034 & 0.000012 & 0.000147 \\
Stresses & $\boldsymbol{\sigma}_{23}$ & -0.000054 & 0.000074 & 0 \\
$(\mathrm{~N} /$ & $\boldsymbol{\sigma}_{33}$ & 0.5973 & -0.00320 & -0.1364 \\
$\left.\mathrm{~mm}^{2}\right)$ & & & & \\
\hline
\end{tabular}

We have proves in this paper of the influence of new Composite-shell stiffness coefficients obtained by an original shell model in mechanical behavior of LCST. We have used some MATLAB scripts to test a conventional algorithm as in [5], [29]. In this work,we proposed a new constitutive relation for composite shell tube using the method developed by W.C. Chan and K.C, Dermirhan [26] rarely implemented in literature. The previous LCEs based on K-L and R-M neglected D and E sub-matrices. Notice that these square matrices exist by the presence of third fundamental form in the kinematic equation used in this work and are very capital for better accurate results in LCS. Our study is based on some assumptions presented above. One of these hypothesis stipulate that the transverse stresses are not neglected. Some twodimensional analyses of laminated shell do not use those assumptions.

Moreover, most of LCEs used do not have strong scientific basis since they introduce a correction factor [13], [30], [31]. Our LCEs are more general as they contain additional sub-matrices D, E to those found in classical laminated shell theories. Moreover, they are obtained using original kinematic equations which are mathematically and mechanical justified without any ad hoc assumptions on transverse fiber's behavior. When the thickness ratio is greater, or equal to 0.1 , $D_{i j} / A_{i j}$ is in the order of $10 . D_{i j} / B_{i j}$ in the order of $100, E_{i j} / A_{i j}$ in the order of $100, E_{i j} / B_{i j}$ in the order of 1000 .

\section{CONCLUSION}

In this paper a new laminate constitutive equation (LCE) was employed for to first time to analyze the mechanical behavior of composite tube through computational tool such as Matlab. This LCE is developed by applying N-T's shell model. Moreover it is physically realistic and is able to represent more generally some information on the behavior of CT. Some test cases were achieved and the results obtained using our analytical formulations are consistent and coherent with the literary informations. Therefore the Matlab tool used here is a good alternative to predict the mechanical behavior of general thin and moderately thick multi-layered composite tube. It was clearly shown that when the ratio-thickness $\chi=\frac{h}{2 R}$ becomes greater, the behavior of tube is influenced by the contribution of some new mechanical couplings such as extensional-gauss, bending-shearing, gauss bendingshearing, shearing. Those couplings are not taken into account for some laminated composite shell models and their derivatives cited above. Transverse stresses were also analytically computed while taking into account the plane stresses components, $\mathrm{ABCDE}$ matrix and the geometries of laminated shell [4]. The results obtained by this formulation showed that the normal stresses component are not zero as suggested by LCS model based on R-M assumptions. The predicting ability of $\mathrm{ABCDE}$ matrix and transverse stresses relations for anisotropic linear elastic shell is also a prove. It appears that the shear vary linearly through the thickness as compared to 3D thick shell equations. The N-T's model brings a unique ability to find all the transverse shear stresses components through the thickness. Though the number of applications in this work may seem insufficient, it will surely aid structural engineers during the conceptual and preliminary design to gain more precision in predicting the behavior of a material. The study can be extended to tapered tube and curved tube using our constitutive relation. Furthermore, numerical techniques such as those recently developed by [32], [33] will certainly be pursued.

\section{ACKNOWLEDGMENT}

The authors declare that they have no known competing financial interests or personal relationships that could have appeared to influence the work reported in this paper. 


\section{REFERENCES}

[1] N. A. Ngatcha, "Mathematical Formulations of laminated Composite Shells for application in marine industries," Master's thesis, Laboratory of E3M, University of Douala, Douala Cameroon, 2019.

[2] P. B. Gning and M. Tarfoui, "Damage development in thick composite tubes under impact loading and influence on implosion pressure: experimental observations," Composites: part B, vol. 36, pp. 306-318, 2005.

[3] D. Shringi, S. Panwar and P. Sharma, "Optimization of Angular Orientation of Composite Laminates," International journal of Enhanced Research in Science Technology\&Engineering, vol. Vol. 3, no. Issue 3, pp. 307-316, March 2014.

[4] N. R. Ngatcha, G. R. Ngouanom and N. Pandong, "Two dimensional shell model to study static analysis of mechanical behavior of materials composite," submitted for publication, 2021.

[5] A. Ramsaroop and K. Kanny, "Using Matlab to Design and Analyse Composite," Engineering,, vol. 2, pp. 904-916, 2010.

[6] W. S. Chan and K. C. Demirhan, "A Simple Closed-Form Solution of Bending Stiffness for Laminated Composite Tubes," Journal of reinforced plastics and composites, vol. 19, no. Issue 4,, pp. 278-291, 2000.

[7] A. Jonnalagadda, A. Sawant, S. Rohde, B. Sankar and P. J. Ifju, "An analytical model for composite tubes with bend-twist coupling," Composite Structures, vol. 131, p. 578-584, 2015.

[8] V. Titaa, J. M. F. Caliri and J. E. Massaroppi, "Theoretical Models to Predict the Mechanical Behavior of Thick Composite Tubes," Materials Research, vol. 15, no. 1, pp. 70-80, 2012.

[9] A. Muhammad, D. Faramarz, H. Ijaz, A. A. ,. Muhammad, M. U. Rashid and T. Mabrouki, "Numerical Modeling the Effects of Chamfer and Hone Cutting Edge Geometries on Burr Formation," WSEAS Transactions on Applied and Theoretical Mechanics, vol. 15, no. 17, pp. 151-156, 2020.
[10] S. Suresh and P. Akshaykumar, "Numerical and Experimental Analysis of Perforated Type of Heat Sink," WSEAS Transactions on Heat and Mass Transfer, vol. 14, no. 11, pp. 92-97, 2019.

[11] D. Rabin, B. Somnath, M. Arindam, M. Snehamoy and R. Debashis, "Effects of Cross Jet on Turbulent Main Stream Flow in a NonCircular Elbow - A Numerical Approach," WSEAS Transactions on Heat and Mass Transfer, vol. 15, no. 17, pp. 83-98, 2020.

[12] K. Kinde and C. Kyoung-Sik, "Buckling characteristic of multi-laminated composite elliptical cylindrical shells," Int J Adv Struct Eng, vol. 7, pp. 1-10, 2015.

[13] T. Kant and M. Menon, "Higher-Order theories for composite and sandwich cylindrical shells with $\mathrm{C}^{\circ}$ finite element," Computers and structure, vol. 33, no. 5, pp. 1191-1204, 1989.

[14] A. Murthy and T. Reddy, "A higher order theory for lamianted composite cylindrical shells," Journal Aeronautical society ,, pp. 161-171, 1986.

[15] J. Whitney and C. Sun, "A refined theory for laminated anisotropic cylindrical shells," Journal of Apllied Mech, vol. 41, pp. 471-476, 1974.

[16] S. Ambartsumyan, "A refined theory of anisotropic shells," FTD-MT-24-1699-71, Ohio, 1969.

[17] E. Widera and S. W. Chung, "A theory of nonhomogeneous ansitropy cylindrical shells," $J$ Appl Mech, vol. 21, pp. 378-399, 1970.

[18] M. Sayir and M. Motavalli, "Fiber-reinforced Laminated composite tubes with free ends under uniform internal pressure," Journal of Mechanics and Physics of Solids, vol. 43, no. 11, pp. 1691-1725, 1995.

[19] J. Q. Tarn and Y. Wang, "Laminated Composites tubes under extension,torsion, bending shearing and pressuring: A state space approach," International journal of solid and structures, vol. 38, no. 2, pp. 9053-9075, 2000.

[20] M. H. Hasan and D. Mondal, " Numerical Investigation of Finned-tube Heat Exchanger with Circular, Elliptical \& Rectangular Tubes," 
WSEAS Transactions on Heat and Mass Transfer, vol. 15, no. 7, pp. 41-49, 2020.

[21] V. Ivan, "Modeling and Numerical Simulation of the Turbulent Two-Phase Jet Confined in the Cylindrical Channel," WSEAS Transactions on Heat and Mass Transfer, vol. 15, no. 19, pp. 151162, 2020.

[22] R. Nzengwa and S. Tagne, "A two-dimensional model for linear elastic thick shells," International Journal of solid and structures, vol. 36, pp. 5141-5176, 1999.

[23] A. Ngatcha, "General Constitutive Relations For Mechanical Analysis Anisotropic Laminated Elastic Shells," National higher polytechnic school of Douala, unpublished, Douala, Cameroon, 2021.

[24] A. Ngatcha, "Some analysis of Laminated anisotropic shells according to first order shear deformation theory," Unpublished, Douala, Cameroon, 2021.

[25] N. Ngatcha, "2D/3D mathematical modelings of static and dynamic behavior of Laminated Composite Shells," Submited.

[26] W. S. Chan and K. Demirhan, "A Simple ClosedForm Solution of Bending Stiffness for Laminated Composite Tubes," Journal of reinforced plastics and composites, vol. 19, no. 4, pp. 278-291, 2000.

[27] C. Lin and W. Chan, "A simple analytical method for analyzing laminated composite elliptical tubes," in Proceedings of 17th technical conference,American Society of composites, 2003.

[28] Y. Stavsky, "Bending and Stretching of Laminated Anisotropic Plates," ASCE, Journal of the Engineering Mechanics Division, vol. 87, no. 6, p. 31,1961

[29] K. Kaw, Mechanics of Composite materials", 2006.

[30] J. Almeida, L. Bittrich, E. Jansen, V. Tita and Spickenheuer, "A. Buckling optimization of composite cylinders for axial compression: A design methodology considering a variable-axial fiber layout," Compos. Struct., 2019.
[31] C. Bert, "Structural theory for Laminated Anisotropic Elastic Shells," Journal of composite Materials, vol. I, p. 414, 1967.

[32] A. G. Feumo, R. Nzengwa and A. J. Nkongho, "Finite element model for linear elastic thick shells using gradient recovery Method," Hindawi, Mathematical problems in engineering, vol. 2017, p. 14, 2017.

[33] A. Nkongho, R. Nzengwa, J. C. Amba and A. C. Ngayihi, "Approximation of linear elastic shells by curved triangular finite elements based on elastic thick shells theory," Mathematical Problems in Engineering, vol. 2016, 2016.

Author Contributions: Please, indicate the role and the contribution of each author:

Ngatcha Ndengna Arno Roland derived the mathematical equations, conducted the simulation and the optimization, and wrote the paper.

Joel Renaud Ngouanom Gnidakouong designed the work, helped in algorithm writing, wrote the paper and corresponded with the editor. Achille Njomoué Pandong designed the work. Mbangue Ekmon wrote the algorithm

\section{Creative Commons Attribution License 4.0 (Attribution 4.0 International, CC BY 4.0)}

This article is published under the terms of the Creative Commons Attribution License 4.0 https://creativecommons.org/licenses/by/4.0/deed.en US 